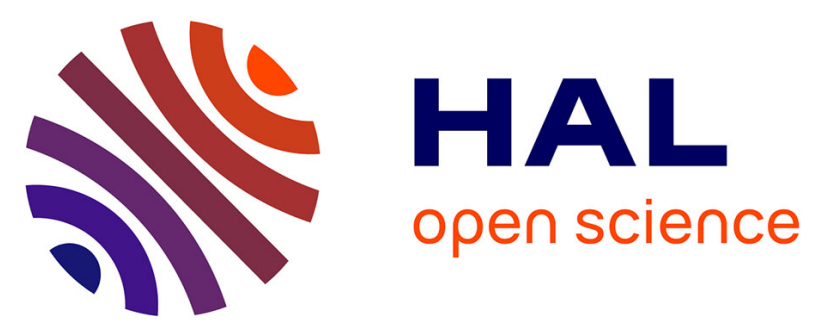

\title{
Assessing diversity and biogeography of aerobic anoxygenic phototrophic bacteria in surface waters of the Atlantic and Pacific Oceans using the Global Ocean Sampling expedition metagenomes
}

Natalya Yutin, Marcelino Suzuki, Hanno Teeling, Marc Weber, J Craig Venter, Douglas B Rusch, Oded Béjà

\section{To cite this version:}

Natalya Yutin, Marcelino Suzuki, Hanno Teeling, Marc Weber, J Craig Venter, et al.. Assessing diversity and biogeography of aerobic anoxygenic phototrophic bacteria in surface waters of the Atlantic and Pacific Oceans using the Global Ocean Sampling expedition metagenomes. Environmental Microbiology, 2007, 9, pp.1464 - 1475. 10.1111/j.1462-2920.2007.01265.x . hal-03012626

\author{
HAL Id: hal-03012626 \\ https://hal.science/hal-03012626
}

Submitted on 18 Nov 2020

HAL is a multi-disciplinary open access archive for the deposit and dissemination of scientific research documents, whether they are published or not. The documents may come from teaching and research institutions in France or abroad, or from public or private research centers.
L'archive ouverte pluridisciplinaire HAL, est destinée au dépôt et à la diffusion de documents scientifiques de niveau recherche, publiés ou non, émanant des établissements d'enseignement et de recherche français ou étrangers, des laboratoires publics ou privés. 


\section{Assessing diversity and biogeography of aerobic anoxygenic phototrophic bacteria in surface waters of the Atlantic and Pacific Oceans using the Global Ocean Sampling expedition metagenomes}

\author{
Natalya Yutin, ${ }^{1}$ Marcelino T. Suzuki, ${ }^{2 *}$ \\ Hanno Teeling, ${ }^{3}$ Marc Weber, ${ }^{3}$ J. Craig Venter ${ }^{4}$ \\ Douglas B. Rusch ${ }^{4}$ and Oded Béjà ${ }^{\text {** }}$ \\ ${ }^{1}$ Biology Department, Technion - Israel Institute of \\ Technology, Haifa 32000, Israel. \\ ${ }^{2}$ Chesapeake Biological Laboratory, University of \\ Maryland Center for Environmental Sciences, PO Box \\ 38, Solomons MD 20688, USA. \\ ${ }^{3}$ Department of Molecular Ecology, Microbial Genomics \\ Group, Max Planck Institute for Marine Microbiology, \\ Celsiusstrasse 128359 Bremen, Germany. \\ ${ }^{4} \mathrm{~J}$. Craig Venter Institute, Rockville, MD 20850, USA.
}

\section{Summary}

Aerobic anoxygenic photosynthetic bacteria (AAnP) were recently proposed to be significant contributors to global oceanic carbon and energy cycles. However, AAnP abundance, spatial distribution, diversity and potential ecological importance remain poorly understood. Here we present metagenomic data from the Global Ocean Sampling expedition indicating that AAnP diversity and abundance vary in different oceanic regions. Furthermore, we show for the first time that the composition of AAnP assemblages change between different oceanic regions with specific bacterial assemblages adapted to open ocean or coastal areas respectively. Our results support the notion that marine AAnP populations are complex and dynamic and compose an important fraction of bacterioplankton assemblages in certain oceanic areas.

\section{Introduction}

Since their rediscovery in the marine environment (Kolber et al., 2000; 2001), aerobic anoxygenic photosynthetic bacteria $(A A n P)$ were reported to exist in a variety of coastal and oceanic environments. These photoheterotro-

Received 7 December, 2006; accepted 19 January, 2007. *For correspondence. E-mail suzuki@ cbl.umces.edu; Tel. (+1) 410326 7291; Fax (+1) 410326 7341; E-mail beja@tx.technion.ac.il; Tel. (+972) 4829 3961; Fax (+972) 48225153. phs were detected using various techniques ranging from infrared fast-repetition-rate analysis of variable bacteriochlorophyll-a (BChla) fluorescence (Kolber et al., 2000; 2001; Koblízek et al., 2005; 2006), cultivation (Allgaier et al., 2003), PCR targeting of photosynthetic reaction centre genes (Béjà et al., 2002; Oz et al., 2005; Yutin et al., 2005), real-time PCR (Schwalbach and Fuhrman, 2005; Du et al., 2006), environmental genomics (Béjà et al., 2002; Oz et al., 2005; Waidner and Kirchman, 2005; Yutin et al., 2005) and direct counts using infrared fluorescence microscopy (Schwalbach and Fuhrman, 2005; Cottrell et al., 2006).

Despite these efforts, the abundance and importance of AAnPs to the flow of energy and carbon in the ocean remain poorly understood (Goericke, 2002; Schwalbach and Fuhrman, 2005; Schwalbach et al., 2005). Using epifluorescence microscopy and real-time PCR, AAnPs were reported to consist of a smaller portion (up to $5 \%$ ) of the total prokaryotic cells in the Pacific Ocean (Cottrell et al., 2006) than originally ('at least 11\%') reported (Kolber et al., 2001) and to range from $2 \%$ to $16 \%$ in the Atlantic Ocean (Cottrell et al., 2006; Sieracki et al., 2006). Furthermore, a study by Goericke (2002) using BChla measurements suggested that the contribution of BChladriven anoxygenic bacterial photosynthesis in the ocean to the conversion of light-energy is substantially lower than the previously suggested global average of $5-10 \%$ (Kolber et al., 2000; 2001). These contradictory findings have at least two explanations: (i) each technique brings a certain estimation error due to inherent features, i.e. real-time PCR studies are biased due to varying binding efficiencies of the chosen primers (Yutin et al., 2005), and epifluorescence microscopy is hampered by the low levels of BChla in cells as well as non-specific detection of picocyanobacteria; (ii) AAnP communities are dynamic and may vary between regions and seasons.

Until now, the diversity of marine AAnP has been mainly estimated by directly amplifying pufM genes, encoding the $M$ subunit of the anoxygenic photosynthetic reaction centre from environmental samples (Béjà et al., 2002; Oz et al., 2005; Schwalbach and Fuhrman, 2005; Yutin et al., 2005; Du et al., 2006), or by screening pufM genes in bacterial artificial chromosome (BAC) libraries (Béjà et al., 
2 N. Yutin et al.

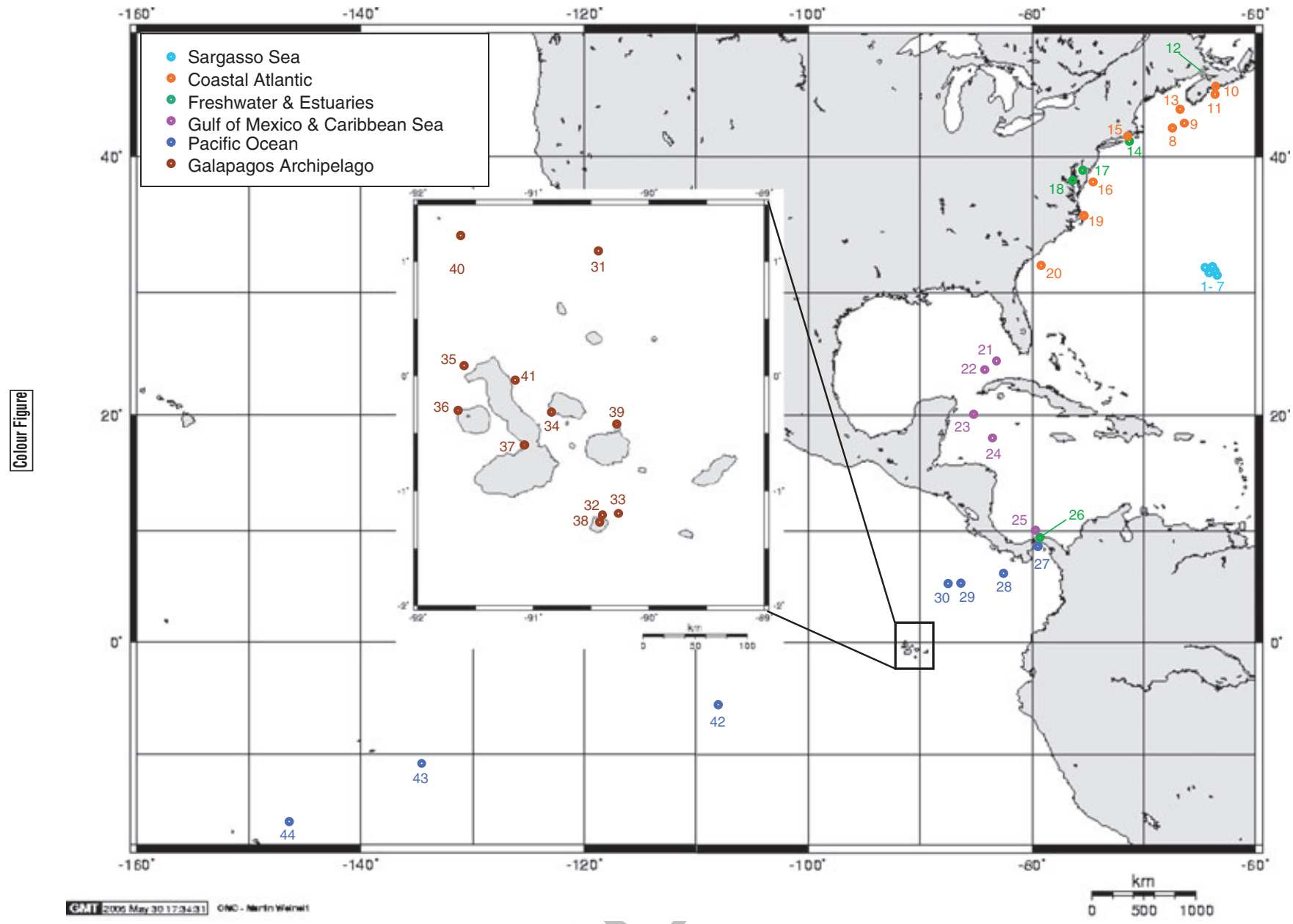

Fig. 1. The GOS transect map. The sites are numbered according to Table S1 (GOS sampling site descriptions). Different colours are used to indicate different types of environments.

2002; Oz et al., 2005; Yutin et al., 2005). These studies led to the discovery of novel AAnPs belonging to different groups of Alpha- and Gammaproteobacteria (Béjà et al., 2002; Oz et al., 2005; Yutin et al., 2005). However, due to PCR- and cloning biases (Yutin et al., 2005), it is difficult to estimate the proportions of different lineages within the AAnP population using these methods. In order to overcome some of the PCR-based limitations, we have used metagenomic shotgun data from the recent Global Ocean Sampling (GOS) expedition (Rusch et al., 2007; Yooseph et al., 2007) to characterize the distribution, composition and abundance of marine AAnPs.

\section{Results and discussion}

The GOS project produced a total of 7.6 million random sequence reads, yielding approximately six Gbp of assembled environmental DNA sequence from the North Atlantic Ocean, the Panama Canal, and East and central Pacific Ocean gyre (Fig. 1; see also Table S1 for sampling site locations and characteristics). In order to increase the coverage of particular genomes, sequence data from all sampling sites were combined for assembly (Rusch et al., 2007; Yooseph et al., 2007).

Using the PufM protein as a probe for anoxygenic photosynthetic bacteria (see Experimental procedures), 99 singletons and scaffolds (hereafter 'scaffolds') containing pufM fragments were extracted from the GOS assembled data (Table S2). The length of these scaffolds ranged from 452 to $21305 \mathrm{bp}$ and 575 sequence reads (hereafter 'reads') were assembled in these scaffolds.

\section{Aerobic anoxygenic photosynthetic bacteria diversity}

In order to investigate the AAnP community composition, a phylogenetic tree was reconstructed from the pufM sequences found on the scaffolds. The results of the pufM phylogenetic analysis were combined with an analysis of the puf-operon structure that allowed discrimination of almost all pufM-containing scaffolds into 12 phylogroups 
(Figs 2 and 3), and also corroborated by oligonucleotide frequency analysis (see below). The distribution of the shotgun sequence data between these phylogroups is shown in Table 1. Although all reads were pooled during the assembly, no scaffolds composed of reads from both anoxic and oxic samples were obtained. Apart from scaffolds of the single anoxic station (discussed separately below), 85 scaffolds were assembled from the remaining 356 reads (Table 1 ). In oxic environments, only two and four reads were found belonging to phylogroups $\mathrm{J}$ and $\mathrm{L}$ respectively, and no reads were found related to phylogroups $F, H$. Thus, phylogroups $F, H, J$ and $L$ were considered as minor groups in these oxic samples.

The four most abundant phylogroups, A, B, C and D, have no cultured representatives. Moreover, these groups were almost completely missed by previous PCR-based surveys that used earlier versions of pufM primers (Nagashima et al., 1997; Achenbach et al., 2001; Béjà et al., 2002; Karr et al., 2003; Oz et al., 2005), as several base pair mismatches exist to genes in these groups. However, more recent pufM primers (Schwalbach and Fuhrman, 2005; Yutin et al., 2005) do recognize these groups. Several unusual features have been revealed from an analysis of the puf-operons of these phylogroups (Fig. 3); (i) the absence of pufA and pufB genes (encoding proteins for light-harvesting complex 1 that usually surround the photosynthetic reaction centre) in groups $A$ and $\mathrm{B}$. This operon organization has, so far, not been observed in any cultured organism. It is important to note here that the real AAnP capacity could not be proven based on genomics alone and more research is needed to find if these operons are indeed active; (ii) the presence of the pufX gene in the puf-operons of bacteria from group $A$. Although until recently, the presence of the pufX gene had only been reported for the anaerobic Rhodobacter lineage, evidences of puf $X$ have been reported for other uncultured bacteria from oxic estuarine (Waidner and Kirchman, 2005) and marine (Yutin and Béjà, 2005) environments. Based on our data set, we propose that PufX-containing reaction centres are common among marine AAnP bacteria, as it was present in 35 of the 85 AAnP scaffolds described; (iii) group D bacteria have a unique order of genes encoding the reaction centre core proteins because all three subunits of the reaction centre are colocated within the same operon (pufLMH).

Based on reads proportions within a given station (Fig. 4), phylogroups A, B, C and D were estimated to be prevalent in the majority of pelagic AAnP communities (Sargasso Sea samples and almost all Pacific samples, including those off the Galapagos Islands; Fig. 4). As these groups were probably missed by most PCR-based AAnP diversity studies, the significance of AAnP bacteria in open ocean microbial communities might have been underestimated so far.
Phylogroup E contains the pufX gene and was mainly found in several stations at the North-western Atlantic coast. There is, however, a BAC clone (EBAC60D04) with 99\% DNA identity to one of the phylogroup $E$ scaffolds that has been obtained from the Pacific Ocean (Béjà et al., 2002).

Phylogroup G represents Roseobacter-like bacteria. One of the scaffolds from this group is identical to the Red Sea (Oz et al., 2005) environmental BAC clone eBACred25D05, and another one is identical to the Mediterranean Sea BAC clone BACmed 31B01 (unpublished data). Members of the Roseobacter lineage are well known to be represented across a variety of marine habitats (Buchan et al., 2005) and our observations support this notion as group $\mathrm{G}$ bacteria were mainly observed at coastal and open water stations in the Pacific as well as the Atlantic Ocean.

The closest cultured relatives of group I bacteria are Betaproteobacteria HTCC528 from a freshwater lake (Page et al., 2004), Rhodoferax antarcticus from an Antarctic microbial mat (Madigan et al., 2000), and Rhodoferax fermentans isolated from a sewage ditch (Hiraishi et al., 1991). Based on this high similarity, phylogroup I likely represents Betaproteobacteria scaffolds. Rhodoferax-related bacteria are found widely distributed in freshwater environments (Glockner et al., 2000; Page et al., 2004) and accordingly, GOS sequences belonging to this group were only detected in estuarine or freshwater samples (Fig. 4). One estuarine fosmid clone [DelRiverFos06H03 (Waidner and Kirchman, 2005)] is also affiliated with these sequences.

Phylogroup K contains Gammaproteobacteria representatives [Congregibacter litoralis KT71 (Eilers et al., 2001) and BAC clones EBAC65D09 and EBAC29C02 (Béjà et al., 2002)], all related to the OM60 clade (Rappé et al., 1997). Despite their close relationships based on pufM phylogeny, AAnPs in this group possess two different types of puf-operon structures: some have pufC downstream of pufM while others have pufA and pufB (Fig. 3 ) indicating that this group might in fact be polyphyletic. Members of group K were found at the North-western Atlantic coast and at some stations off the Galapagos Islands.

\section{Anaerobic photosynthetic scaffolds assembled from an anoxic sample}

The single anoxic sample in this set of the GOS expedition (hypersaline lagoon, Galapagos; dissolved oxygen, $0.06 \mathrm{mg} \mathrm{l}^{-1}$ ), contributed 219 reads to our data set (Table 1). Half or these reads were assembled in a 21 255-bp-long scaffold (\#1096627135419) belonging to group $\mathrm{H}$ (Fig. 2). This group represented the most abundant anoxygenic phototrophs at this station, and currently contains no known cultured relatives. The puf-operon 
emi_1265

$4 \quad$ N. Yutin et al.

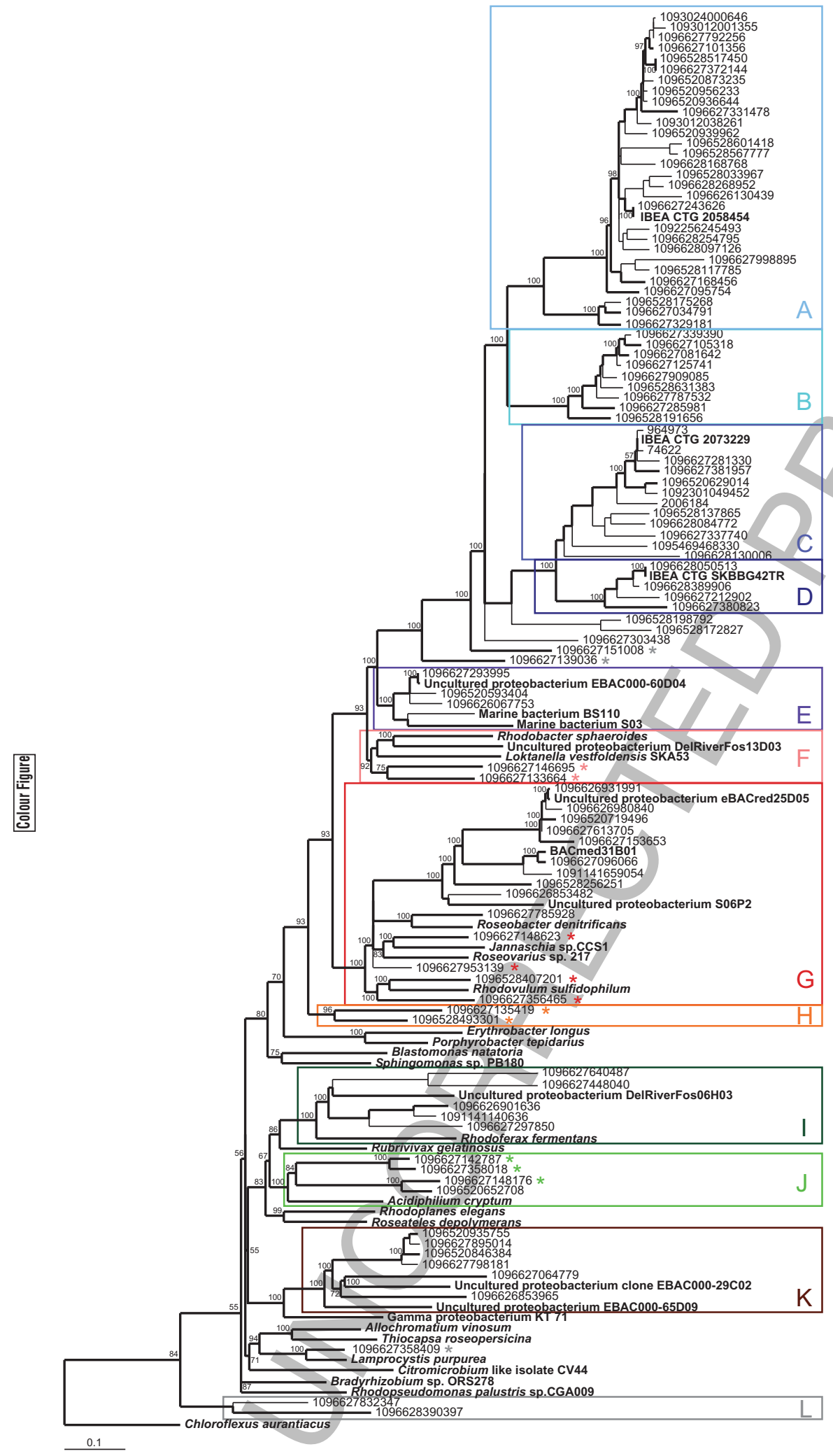

Fig. 2. pufM phylogenetic tree. The tree is based on a Bayesian tree to which short sequences were added by ARB_PARSIMONY.

Reference sequences retrieved from the GenBank are marked in bold. IBEA_CTG clones belong to the Sargasso Sea project (Venter et al., 2004) whose sequence data were included in GOS assembly. Branches found on the initial Bayesian tree are shown in bold lines. The numbers on nodes represent branch confidence values. Asterisks indicate scaffolds assembled by reads from the anoxic sample. Coloured boxes mark the

12 phylogroups defined in this study.

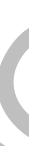


Phylogroup A $\square \square L \mathbf{m} \times \square \square$

Phylogroup B $\mathrm{L}$
$\mathrm{m}$$\square \square$

Phylogroup C $Z$ Z $B$ B $L \longrightarrow M$

Phylogroup D $\mathrm{Z}>\mathrm{QBB}, \mathrm{L} \backslash \mathrm{M}>\mathrm{H}>641 \mathrm{C}$

Phylogroup E

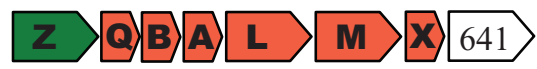

Phylogroup F $L M \times 641$

Phylogroup G

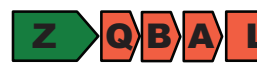
L) M $>641$

Phylogroup $\mathrm{H}$ $Z B A, L>C$

Phylogroup I $Z B A D M C$

Phylogroup J $Z B A, L M C$ Phylogroup K

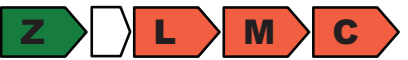
$z>L>M>B$

Phylogroup L

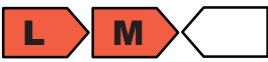

Fig. 3. Diversity of photosynthetic operonal organization revealed in the GOS data set. puf-operons are shown in red. Z, chlorophyllide reductase $Z$ subunit, is marked in green. 641 , deoxyxylulose-5-phosphate synthase (orf 641). Other genes are labelled in white.

structure of this scaffold is pufBALMC (Fig. 3). Scaffold number 1096627139036 represents the second most abundant bacterium at this station and is somewhat related to the Rhodobacter clade with a puf-operon structure identical to that of Rhodobacter species: pufQBALMX. Currently no cultured strains closely related to this phylotype exist. Other abundant pufM-containing scaffolds found at station 38 were related to Loktanella vestfoldensis (phylogroup F), Rhodovulum sulfidophilum (phylogroup G), Antarctic clones LFc1 and LFc15 (Karr et al., 2003) (phylogroup J; the sequences from these clones were short and are not shown in Fig. 2), and Lamprocystis purpurea (scaffold 1096627358409). Not surprisingly, anoxygenic phototrophs at this station were quite unique as no anoxygenic phototrophs found at this anoxic sample were observed in any of the oxic samples.

The assembly efficiency at this sample was remarkably higher than in the oxic samples. Four nearly completed genomes and the highest ratio of unassembled/ assembled in $>10000$-bp-long scaffolds reads were found here (Rusch et al., 2007) and no singletons coming from station 38 were observed in the represented data set (Table S1). This success of assembly may be attributed to lower species richness at this station and/or to the large sequencing effort performed at this station (694642 reads).

Oligonucleotide frequency analysis of pufM-containing scaffolds from the GOS data set

The validity of the phylogroups defined on pufM phylogenetic reconstruction and operon organization was further evaluated by genomic signature analysis. As comparative genomics has revealed in recent years, the frequencies of short oligonucleotides in genomes act like a speciesspecific fingerprint and furthermore carry a weak phylogenetic signal (Pride et al., 2003). While the analysis of such genomic signatures cannot compete with genebased phylogenetic reconstruction, regarding the sophistication of the underlying mathematics and thus resolution, it has the advantage of not being limited to genes. Instead, the entire DNA sequence can be analysed which is particularly interesting in metagenomics,

Table 1. Summary of pufM-associated data extracted from the GOS data set.

\begin{tabular}{|c|c|c|c|c|c|c|}
\hline \multirow[b]{2}{*}{ Phylogroup } & \multicolumn{2}{|c|}{ Total } & \multicolumn{2}{|c|}{ Oxic } & \multicolumn{2}{|c|}{ Anoxic } \\
\hline & Reads & Scaffolds & Reads & Scaffolds & Reads & Scaffolds \\
\hline$A$ & 78 & 30 & 78 & 30 & 0 & 0 \\
\hline$B$ & 47 & 9 & 47 & 9 & 0 & 0 \\
\hline $\mathrm{C}$ & 36 & 12 & 36 & 12 & 0 & 0 \\
\hline D & 29 & 4 & 29 & 4 & 0 & 0 \\
\hline$E$ & 61 & 3 & 61 & 3 & 0 & 0 \\
\hline $\mathrm{F}$ & 9 & 2 & 0 & 0 & 9 & 2 \\
\hline$G$ & 63 & 14 & 53 & 10 & 10 & 4 \\
\hline $\mathrm{H}$ & 107 & 2 & 0 & 0 & 107 & 2 \\
\hline 1 & 14 & 5 & 14 & 5 & 0 & 0 \\
\hline $\mathrm{J}$ & 18 & 4 & 2 & 1 & 16 & 3 \\
\hline K & 26 & 6 & 26 & 6 & 0 & 0 \\
\hline L & 4 & 2 & 4 & 2 & 0 & 0 \\
\hline Others & 83 & 6 & 6 & 3 & 77 & 3 \\
\hline Sum & 575 & 99 & 356 & 85 & 219 & 14 \\
\hline
\end{tabular}




\section{N. Yutin et al.}
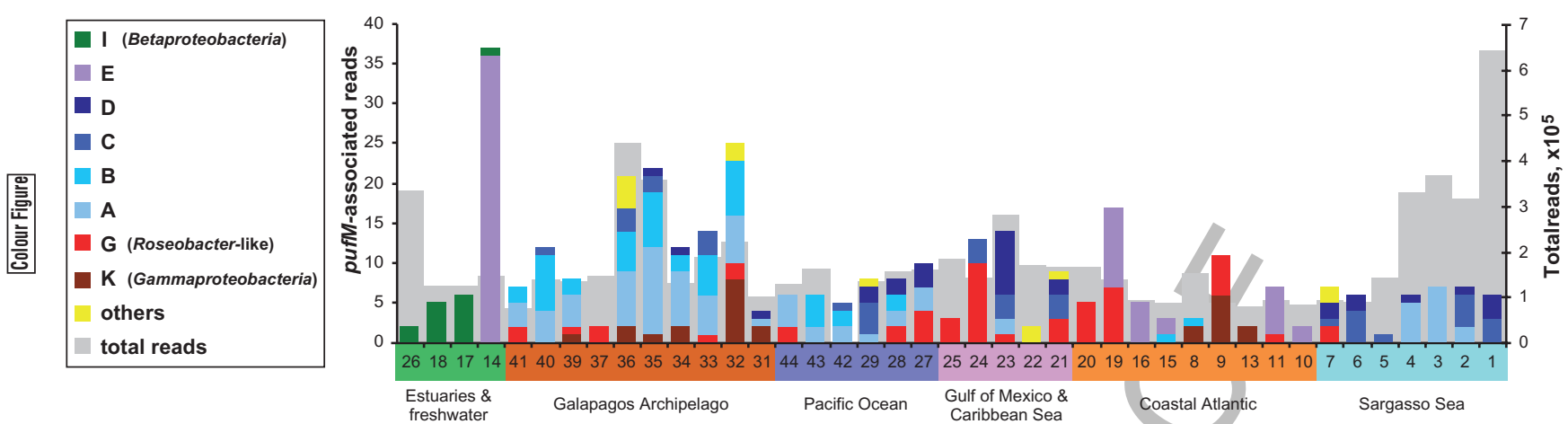

Fig. 4. AAnP population compositions along the GOS transect. Colours used to represent different types of environments are the same as in Fig. 1, and colours representing the eight major phylogroups are according to those used in Fig. 2. pufM-associated reads are reads included in pufM-containing scaffolds. Note that samples 5, 6 and 7 are different size fractions from the same station: sample 5, 20-3 $\mu$; sample 6 , 3-0.8 $\mu \mathrm{m}$; sample 7, 0.8-0.1 $\mu \mathrm{m}$.

where frequently only short fragments or only partial genes are obtained. Due to the shortness of many of the scaffolds in this study, only di- and trinucleotide frequencies could be used because statistics on longer oligonucleotides require longer sequences. While this did not allow computing well-separated coherent de novo clusters, a cluster analysis of the data revealed striking con-

2 gruities with the pufM phylogenetic reconstruction (Fig. 5). Sixty-one per cent of the scaffolds formed clusters uniquely represented by sequences from distinct phylogroups assigned by phylogenetic and operon analysis.

\section{Aerobic anoxygenic photosynthetic bacteria biogeography}

Although the occurrence of specific gene-anchored reads and scaffolds in shotgun sequence data is a likelihood event (especially for a rare gene as pufM), our analysis of AAnP community composition at different stations reveal some interesting trends (Fig. 4). The Roseobacter-related phylogroup $(G)$ appears to be the most ubiquitous across different environments. In addition, phylogroup $\mathrm{G}$ constitutes a significant part of the AAnP communities at mesotrophic stations (stations 24-28 surrounding the Panama Canal; coral reef atoll at station 44; some coastal stations and some stations off the Galapagos Islands) and a minor part of oligotrophic AAnP communities (Pacific Ocean Gyre and Sargasso Sea stations). Phylogroups A and $B$, not previously described, are the main AAnPs in oligotrophic regions. Phylogroups $E$ and $K$ subsume coastal species, whereas phylogroups $C$ and $D$ represent mostly offshore species. Group I bacteria, attributed to a freshwater Betaproteobacteria clade, also composed a significant part of AAnPs in all estuarine samples, indicating that they might thrive in saline environments (the salinity at the station 14 was 26.5 p.p.t.).
Aerobic anoxygenic photosynthetic bacteria abundance estimation

While the GOS expedition was originally intended to the discovery of new genes and organisms, and evaluation of microbial genetic diversity (Rusch et al., 2007), our study was aimed to survey AAnP community compositions and to gain insights on specific AAnP abundances along the GOS transect. An important question in the study of AAnPs is what per cent of total bacteria (or total microbes) in the community AAnPs comprise. We inferred AAnP relative abundances by the relative abundances of anoxygenic photosynthetic genes in these samples using different metrics. In all anoxygenic phototrophs genomes reported to date, the pufM gene was found as a singlecopy gene and was therefore used to estimate AAnP numbers in our samples. Besides the marker for AAnP bacteria, we used the $r e c A$ gene coding a critical DNA repair enzyme and considered to be a single-copy gene present in all bacterial genomes; thus, it is a suitable estimator of total bacterial genomes in the sample (Venter et al., 2004; Howard et al., 2006). As the length of pufM and $\operatorname{rec} A$ genes is, on average, similar, initially we assumed that the ratio between the number of pufM and recA reads reflected the ratio between $A A n P$ and total bacteria in our samples (data not shown).

These pufM and recA reads are meant as sequence reads strictly containing at least a part of the pufM or the recA genes. However, in addition, our data set was composed of scaffolds assembled from different reads from the entire data set, some containing fragments of other genes situated in certain proximity to the pufM or the recA genes. This information was used as a second metric of relative abundance, as common genomes should result in longer scaffolds. All reads (and not just those containing pufM) assembled in pufM-containing scaffolds were counted as 'pufM-associated' reads in Fig. 4. While in 


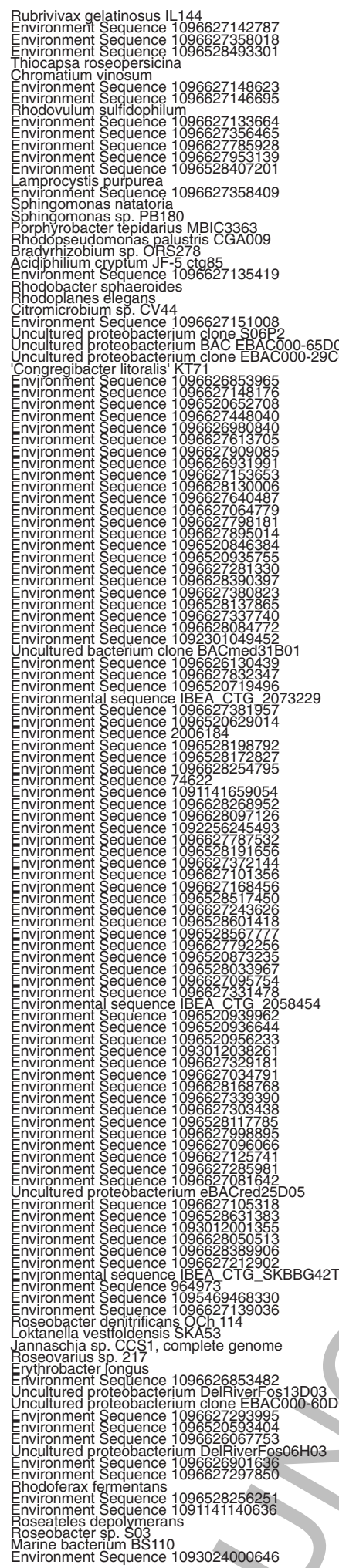

Marine bacterium BS110
Environment Sequence 1093024000646

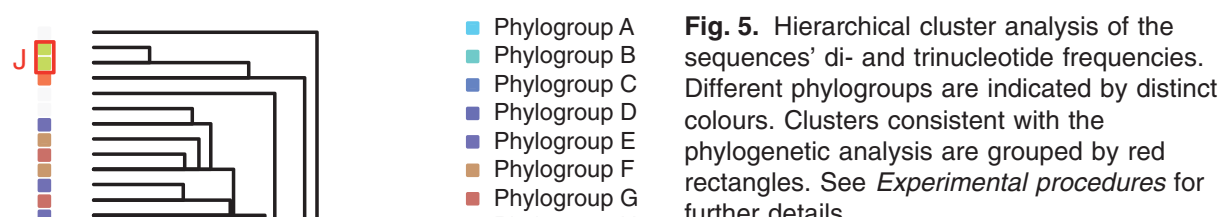

- Phylogroup $\mathrm{G}$

- Phylogroup $\mathrm{H}$

- Phylogroup I

- Phylogroup J

- Phylogroup K

Phylogroup L

Others

further details.

(1)

.

.
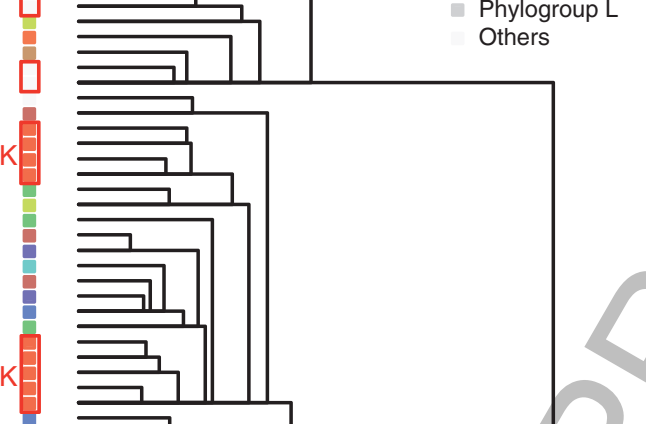

c四

”्य
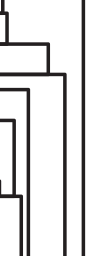

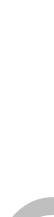

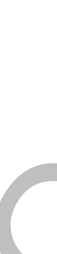

o

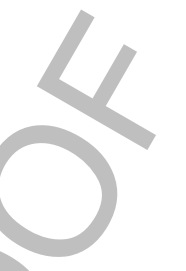


8 N. Yutin et al.

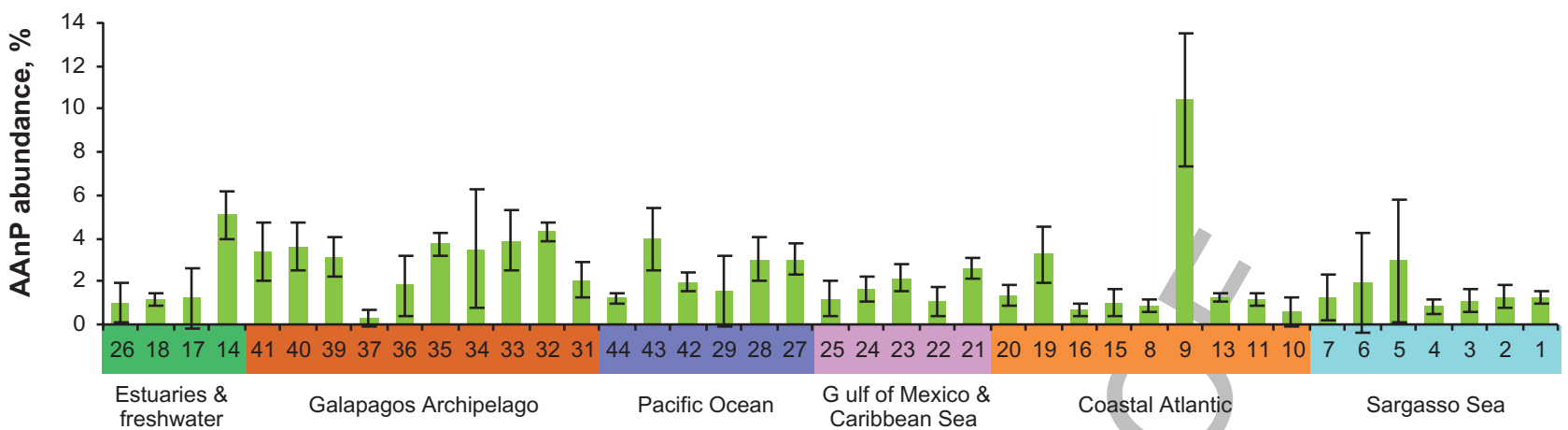

Fig. 6. Estimated AAnP abundances along the GOS transect.

poorly assembled scaffolds (composed of one to two reads, and comprising $69 \%$ of pufM-containing scaffolds) the number of pufM reads and pufM-associated reads are nearly equal, this is not the case in large scaffolds. For instance, the high number of pufM-associated reads at station 14 (Fig. 4) is the result of the assembly of a 17830 -bp-long scaffold, containing 36 (out of 57) reads belonging to this station (Table S2). Again, as abundant genomes should result in longer scaffolds, it was not surprising that $55 \%$ of recA-associated reads in the entire data set were assembled in only 16 of 5104 scaffolds, ranging from 1 to 10723 reads.

A third metric was also developed as measure for approximating the total number of pufM (or recA) reads per station based on the assembled data. This measure, termed 'read equivalents' (see Experimental procedures for details), is not depended (at least, not directly) on the scaffold size, and, thus, is an estimate of total pufM reads in each of the individual stations. The read equivalent measure was developed to approximate the number of reads targeting certain genes from scaffold assembly data. It is based on the number of reads participating in a given scaffold (scaffold size), and on the ratio of scaffold length/gene length. Read equivalents are more suitable for longer scaffolds, where statistic approaches and averaging-like coverage concept are applicable. In our case, 'the end effects' are considerable (only a part of a pufM gene appears on the scaffold). Based on the calculations, short pufM end-sequences in long scaffolds underestimate read equivalents, while longer pufM endsequences in short scaffolds overestimates the measure. Assuming the proportion of these type of sequences are similar for different genes (i.e. $\operatorname{rec} A$ ), the normalization step should compensate for these errors.

Whereas 5104 scaffolds containing recA genes were found in the entire data set, only 99 scaffolds were found containing pufM. Because of this low number of scaffolds, we increased the reliability of our estimations by adding to the analysis two additional AAnP unique markers, namely the puf $L$ gene coding for the $L$ subunit of the anoxygenic photosynthetic reaction centre and the $b c h X$ gene coding for the $X$ subunit of chlorophyllide reductase in the bacteriochlorophyll biosynthetic pathway. Both genes have roughly the same length as pufM and $\operatorname{rec} A$ and, as can be seen in Fig. S1, there was a very high correlation between these three AAnP markers in most stations measured by the number of gene-associated reads, as well as read equivalents. For each sampling station, pufM, pufL and $b c h X$ read equivalents were calculated, normalized by recA read equivalents and averaged to produce the AAnP abundance evaluation shown in Fig. 6. Aerobic anoxygenic photosynthetic bacteria abundance varied between different marine stations. The highest AAnP percentages were observed at a coastal (10\%; station 9, Browns Bank, Gulf of Maine) and an estuarine (5\%; station 14, Newport Harbor) station. In several Pacific Ocean samples, the AAnP abundance was near $4 \%$ (see open ocean station 43 and Galapagos stations 32-35). These estimates therefore imply that AAnPs are found in relatively similar proportions in both oligotrophic and eutrophic environments and are important component of the total upper ocean microbial community.

\section{Potential biases of sampling and metagenomics data set processing}

The results reported here are for samples in the $0.1-0.8 \mu \mathrm{m}$ size range. Aerobic anoxygenic photosynthetic bacteria have been reported to be larger than the average bacterioplankton (Sieracki et al., 2006) and in addition, some AAnPs might be associated with larger particles (as symbionts of eukaryotic cells, or attached to marine snow) and might produce chains as reported for Erythrobacter (Yurkov and Beatty, 1998); see differences in population composition in samples 5, 6 and 7 in Fig. 4, which are different size fractions of the same station). Thus there is a possibility that our estimates of AAnP diversity and relative abundance are underestimates. On the other hand, high cell densities in some water samples may have clogged $0.8 \mu \mathrm{m}$ filters producing a bias towards 
smaller cells. Finally, besides biases introduced by sampling methods, many known biases might result from differential DNA extraction, cloning using $E$. coli as a host, and other common problems associated with metagenomic assembly like chimera formation and, intraspecies sequence variability.

In addition, pooling the raw sequencing results prior to assembly, applied for the first time in this data treatment, raised a new challenging statistical problem. In singlestation metagenomic assembly, scaffold length and coverage are functions of the amount of sequencing performed at the station, of the species richness, and the length and the abundance of particular genomes contributing to the scaffolds. When scaffolds are assembled from reads coming from different sampling sites, lengths and coverages depend on the same parameters, but from all sampling sites combined and thus high abundance of a genome at one of the sampling sites increased the chance of its assembly at all sampling sites. In our case, this meant an increased probability to find the same AAnPs across sampling sites. Fortunately, this did not appear to be case in our study as 72 from the 99 pufMcontaining scaffolds were assembled from reads from single stations. However, this issue remains to be resolved for larger future metagenomic data sets.

Aerobic anoxygenic photosynthetic bacteria relative abundance values calculated in this study are based on approximate relative abundances of pufM-pufL-bchXcontaining bacteria, with the assumption that these genes, as well as the recA gene, are single-copy in their genomes. In most anoxygenic phototrophs genomes reported to date, including the genome of the AAnP Roseobacter denitrificans Och 114 (Swingley et al., 2007), the pufM gene was found as a single-copy gene and was therefore used to estimate AAnP numbers in our samples. However, in two reported cases, Roseobacter litoralis and Staleya guttiformis, the pufM gene was also found on an extrachromosomal linear plasmids (Pradella et al., 2004). The number of copy of these linear plasmids per cell was not determined and currently it is not known how general this phenomenon is.

The recA gene was used to normalize AAnP abundance estimates because these genes are the most often employed single-copy gene normalizers (Venter et al., 2004; Howard et al., 2006). However, other genes than the $\operatorname{rec} A$ gene may be used for the normalization. We checked how our estimates were influenced when alternate 'single-copy protein' genes like rpoB (RNA polymerase B) and gyrA (DNA gyrase subunit A) previously used to estimate the number of genomes represented in metagenomic libraries (Venter et al., 2004). Aerobic anoxygenic photosynthetic bacteria abundances normalized by $r p o B$ and gyrA genes were calculated and compared with those obtained with the $\operatorname{rec} A$ gene (Fig. S2).
The calculations were the same as for $\operatorname{rec} A$, with an additional gene length normalization step, because rpo $B$ and $g y r A$ genes both are significantly longer than the $C$. $1000 \mathrm{bp}$ of recA (c. 3600 and 2700 bp respectively). For most stations, values obtained were similar (within the standard deviations calculated from pufM-pufL-bchX averages using $r e c A$ as normalizer).

As the algorithm for searching recA-containing contigs does not discriminate bacterial RecAs from eukaryotic and archaeal homologues (RAD family proteins), the abundances obtained represent per cents of total cells in the community rather than percents of total bacteria. However, due to the size fractionation we very likely excluded the vast majority of Eukarya from the samples, and thus these numbers are comparable to the percentages of AAnPs measured relative to total (DAPI) bacterial counts. The rpoB (Walsh et al., 2004; Case et al., 2007) and gyrA (Guipaud et al., 1997; Wall et al., 2004) genes may also have close analogues in archaea and plastid DNA.

Although metagenomics has been so far mostly used for culture- and PCR-independent gene discovery, recent studies have used metagenomic assembly for prediction of viral community diversity and species richness (Angly et al., 2006). We believe that our preliminary calculation raises the importance of refined models combining bacterial population structure and diversity parameters using metagenomic data.

\section{Concluding remarks}

Combining the GOS abundance results with the results accumulated using BChla-based biophysical measurements (Kolber et al., 2000; 2001), real-time PCR and infrared fluorescence microscopy (Schwalbach and Fuhrman, 2005; Cottrell et al., 2006; Du et al., 2006), we suggest that AAnP loads vary significantly between different regions and represent a dynamic component of marine bacterioplankton. Furthermore, our results show that not only abundance but also AAnP composition varies between different oceanic regions. This is, to our knowledge, the first time that the AAnP population composition is estimated in a global biogeographical context.

\section{Experimental procedures}

Global Ocean Sampling sample collection, shotgun cloning, primary assembly and extraction of AAnP-related data

Water samples were collected from February 2003 to May 2004 along a North-South transect between $45^{\circ} \mathrm{N}$ in the Atlantic Ocean and $15^{\circ} \mathrm{S}$ in the Pacific Ocean. Samples were collected from a wide range of habitat types, including oceanic and coastal seawater, freshwater and hypersaline lakes, estuaries, and areas surrounding oceanic islands. The 


\section{$10 N$. Yutin et al.}

coordinates and different characteristics of sampling stations are presented in Table S1. Sampling procedures, library construction, shotgun sequencing and assembly are described in Rusch and colleagues (2007). Shotgun data used in this study were obtained mainly from 0.8 to $0.1 \mu \mathrm{m}$ sized planktonic fractions (see Table S1 for sample fraction sizes). The assembly was performed on entire pool of GOS sequence reads, with an overlap cut-off of $98 \%$ identity, whereas minimal length of an overlap was $40 \mathrm{bp}$.

Scaffolds related to anoxygenic bacteria were extracted by a sequence recently reported similarity clustering approach (Yooseph et al., 2007). Briefly, protein sequences produced from the assembled scaffolds were clustered with a nonredundant set of publicly available sequences within the NCBI-nr, NCBI Prokaryotic Genomes, TIGR Gene Indices and Ensemble data sets based on pair-wise sequence similarity. Clustering was based on full-length sequences, rather than domains, and incorporated length-based thresholds to address fragmentary sequences thereby minimizing the clustering of unrelated proteins. In this way, 99 pufMcontaining scaffolds were revealed. Contributions of each sampling station to every scaffold are given in Table S2. Using the methodology, 109 pufL, 109 bchX, 5104 recA, 8392 gyrA and 10482 rpoB gene-containing scaffolds were detected in this data set.

\section{Phylogenetic tree reconstruction}

pufM phylogenetic analysis was initially performed using 36 reference sequences from cultured species and environmental genomic clones retrieved from GenBank and 46 GOS scaffolds containing significant sequence overlap (c. $750 \mathrm{bp}$ ) with the reference sequences [positions homologous to positions 7-736 of the Rhodobacter sphaeroides sequence (AJ010302)]. Using ARB (Ludwig et al., 2004), the GOS scaffold nucleotide sequences were imported into a previously described pufM database (Yutin et al., 2005), translated into amino acids and aligned. Thereafter, the alignment was manually corrected. The resulting protein alignment was used to realign (back-translate) nucleotide sequences in ARB, and this nucleotide alignment was used in all subsequent phylogenetic analyses. Aligned nucleotide sequences were exported using a filter that excluded positions where gaps outnumbered characters, and kept the nucleotides in frame (720 total nucleotide positions). From this filtered alignment a phylogenetic tree was reconstructed by Bayesian inference using the MrBayes 3.0 program (Ronquist and Huelsenbeck, 2003) with the General Time Reversible model and rates varying according to codon positions. Four parallel chains of 1 million generations were run, trees were sampled every 100 generations, and 600 'burnin' trees were excluded from the consensus tree. This consensus tree was imported into ARB and 53 shorter nucleotide sequences were aligned as above and added to the Bayesian tree using the ADD_BY_PARSIMONY algorithm and the same filter.

\section{Calculating AAnP abundances along the GOS transect}

pufM read equivalents at all sampling sites were calculated as described below.
For each (ith) scaffold, its coverage is expressed as:

$a_{i}=N_{i} \cdot L / S_{i}$

where $N_{i}$ is the total number of reads in the ith scaffold, $L$ is the mean read length (842 bp) in the entire data set, and $S_{i}$ is the ith scaffold length.

The total number of bp associated with the pufM sequence at the ith scaffold was defined as:

$B_{i}=g_{i} \cdot a_{i}$

where $g_{i}$ is the length of the pufM fragment on the ith scaffold.

The contribution of $j$ th station reads to the ith scaffold:

$m_{i j}=n_{i j} / N_{i}$

where $n_{i j}$ is the number of reads from the th station participating in the th scaffold; $N_{i}=\Sigma^{j} n_{i j}$.

For each (jth) station, the number of bp associated with a given (ith) pufM fragment is calculated as:

$b_{i j}=B_{i} \cdot m_{i j}$

pufM read equivalents $(r)$ were defined as:

$r_{i j}=b_{i j} / L$

The read equivalents approximate the number of reads containing ith pufM fragment at the jth station. From Eqs 1-5, $r_{i j}=n_{i j} \cdot g_{i} / S_{i}$.

The total number of pufM read equivalents at the $j$ th station:

$$
R_{j}=\sum^{i} r_{i j}
$$

An example of pufM read equivalent calculation for one of the sampling sites is shown in Supplementary materials.

Total numbers of read equivalents for $\operatorname{rec} A$ and all other normalizer genes were calculated. The pufM-based AAnP abundance at each station was estimated as:

$$
A_{j}^{\text {pufM }}=\frac{R_{j}^{\text {pufM }}}{R_{j}^{\text {recA }}} \cdot 100 \%
$$

Additionally, scaffolds containing fragments of pufL and $b c h X$ genes were extracted from the GOS data set. puf $L$ and $b c h X$ read equivalents were calculated; pufL and $b c h X$-based AAnP abundances at each station were estimated as: $A_{j}^{\text {pufl }}=\frac{R_{j}^{\text {pufl }}}{R_{j}^{\text {recA }}} \cdot 100 \% ; A_{j}^{\text {bchX }}=\frac{R_{j}^{\text {bchX }}}{R_{j}^{\text {recA }}} \cdot 100 \%$.

\section{Genome signature analysis}

The DNA sequences of the 99 scaffolds and the 36 reference sequences used in this study were imported into TETRA (Teeling et al., 2004) where four length-independent parameters were computed: relative dinucleotide and trinucleotide frequencies, dinucleotide relative abundances and Markov model-based trinucleotide $z$-scores. These data were exported and imported into Aabel (Gigawiz), where an unweighted hierarchical cluster analysis with the Euclidian distance as distance measure was computed for all 160 data columns. 


\section{Acknowledgements}

We would like to thank B. Fuchs for providing unpublished genome sequences and M. Shmoish for fruitful discussions. This work was supported in part by grant from the Israel Science Foundation, a grant from the Israeli Ministry of Science and Technology and an EMBO YIP award (O.B.), NSF Grant OCE-0550547 (M.T.S.) and by the U.S. Department of Energy Office of Science's Biological and Environmental Research Program grant and the Gordon and Betty Moore Foundation (J. Craig Venter Institute). We thank the Governments of Canada, Mexico, Honduras, Costa Rica, Panama, Ecuador and French Polynesia/France for facilitating sampling activities. All sequencing data collected from waters of the above named countries remain part of the genetic patrimony of the country from which they were obtained.

\section{References}

Achenbach, L.A., Carey, J., and Madigan, M.T. (2001) Photosynthetic and phylogenetic primers for detection of anoxygenic phototrophs in natural environments. Appl Environ Microbiol 67: 2922-2926.

Allgaier, M., Uphoff, H., and Wagner-Dobler, I. (2003) Aerobic anoxygenic photosynthesis in Roseobacter clade bacteria from diverse marine habitats. Appl Environ Microbiol 69: 5051-5059.

Angly, F., Felts, B., Breitbart, M., Salamon, P., Edwards, R., Carlson, C., et al. (2006) The marine viromes of four oceanic regions. PLoS Biol 4: e368.

Béjà, O., Suzuki, M.T., Heidelberg, J.F., Nelson, W.C., Preston, C.M., Hamada, T., et al. (2002) Unsuspected diversity among marine aerobic anoxygenic phototrophs. Nature 415: 630-633.

Buchan, A., González, J.M., and Moran, M.A. (2005) Overview of the marine Roseobacter lineage. Appl Env Microbiol 71: 5665-5677.

Case, R.J., Boucher, Y., Dahllof, I., Holmstrom, C., Doolittle, W.F., and Kjelleberg, S. (2007) The 16S rRNA and rpoB genes as molecular markers for microbial ecology. Appl Environ Microbiol (in press).

Cottrell, M.T., Mannino, A., and Kirchman, D.L. (2006) Aerobic anoxygenic phototrophic bacteria in the MidAtlantic Bight and the North Pacific Gyre. Appl Environ Microbiol 72: 557-564.

Du, H., Jiao, N., Hu, Y., and Zeng, Y. (2006) Real-time PCR for quantification of aerobic anoxygenic phototrophic bacteria based on pufM gene in marine environment. $J$ Exp Mar Biol Ecol 329: 113-121.

Eilers, H., Pernthaler, J., Peplies, J., Glockner, F.O., Gerdts, G., and Amann, R. (2001) Isolation of novel pelagic bacteria from the german bight and their seasonal contributions to surface picoplankton. Appl Environ Microbiol 67: 51345142.

Glockner, F.O., Zaichikov, E., Belkova, N., Denissova, L., Pernthaler, J., Pernthaler, A., and Amann, R. (2000) Comparative 16S rRNA analysis of lake bacterioplankton reveals globally distributed phylogenetic clusters including an abundant group of actinobacteria. Appl Env Microbiol 66: $5053-5065$.
Goericke, R. (2002) Bacteriochlorophyll $a$ in the ocean: is anoxygenic bacterial photosynthesis important? Limnol Oceanogr 47: 290-295.

Guipaud, O., Marguet, E., Noll, K.M., de la Tour, C.B., and Forterre, P. (1997) Both DNA gyrase and reverse gyrase are present in the hyperthermophilic bacterium Thermotoga maritima. Proc Natl Acad Sci USA 94: 10606-10611.

Hiraishi, A., Hoshimao, Y., and Satoh, T. (1991) Rhodoferax fermentans gen. nov. and sp. nov., a phototrophic purple non-sulfur bacterium previously referred to as the 'Rhodocyclus gelatinosus-like' group. Arch Microbiol 153: 330-336.

Howard, E.C., Henriksen, J.R., Buchan, A., Reisch, C.R., Burgmann, H., Welsh, R., et al. (2006) Bacterial taxa that limit sulfur flux from the ocean. Science 314: 649-652.

Karr, E.A., Sattley, W.M., Jung, D.O., Madigan, M.T., and Achenbach, L.A. (2003) Remarkable diversity of phototrophic purple bacteria in a permanently frozen Antarctic lake. Appl Environ Microbiol 69: 4910-4914.

Koblízek, M., Ston-Egiert, J., Sagan, S., and Kolber, Z.S. (2005) Diel changes in bacteriochlorophyll a concentration suggest rapid bacterioplankton cycling in the Baltic Sea. FEMS Microbiol Ecol 51: 353-361.

Koblízek, M., Falkowski, P.G., and Kolber, Z.S. (2006) Diversity and distribution of anoxygenic phototrophs in the Black Sea. Deep Sea Res II (in press).

Kolber, Z.S., Van Dover, C.L., Niderman, R.A., and Falkowski, P.G. (2000) Bacterial photosynthesis in surface waters of the open ocean. Nature 407: 177-179.

Kolber, Z.S., Plumley, F.G., Lang, A.S., Beatty, J.T., Blankenship, R.E., VanDover, C.L., et al. (2001) Contribution of aerobic photoheterotrophic bacteria to the carbon cycle in the ocean. Science 292: 2492-2495.

Ludwig, W., Strunk, O., Westram, R., Richter, L., Meier, H., Yadhukumar, et al. (2004) ARB: a software environment for sequence data. Nucleic Acid Res 32: 1363-1371.

Madigan, M.T., Jung, D.O., Woese, C.R., and Achenbach, L.A. (2000) Rhodoferax antarcticus sp. nov., a moderately psychrophilic purple nonsulfur bacterium isolated from an Antarctic microbial mat. Arch Microbiol 173: 269-277.

Nagashima, K.V.P., Hiraishi, A., Shimada, K., and Matsuura, K. (1997) Horizontal transfer of genes coding for the photosynthetic reaction centers of purple bacteria. $J \mathrm{Mol}$ Evol 45: 131-136.

Oz, A., Sabehi, G., Koblízek, M., Massana, R., and Béjà, O. (2005) Roseobacter-like bacteria in Red and Mediterranean Sea aerobic anoxygenic photosynthetic populations. Appl Environ Microbiol 71: 344-353.

Page, K.A., Connon, S.A., and Giovannoni, S.J. (2004) Representative freshwater bacterioplankton isolated from Crater Lake, Oregon. Appl Env Microbiol 70: 6542-6550.

Pradella, S., Allgaier, M., Hoch, C., Pauker, O., Stackebrandt, E., and Wagner-Dobler, I. (2004) Genome organization and localization of the puf $L M$ genes of the photosynthesis reaction center in phylogenetically diverse marine Alphaproteobacteria. Appl Environ Microbiol 70: 33603369.

Pride, D.T., Meinersmann, R.J., Wassenaar, T.M., and Blaser, M.J. (2003) Evolutionary implications of microbial genome tetranucleotide frequency biases. Genome Res 13: $145-158$. 


\section{$12 N$. Yutin et al.}

Rappé, M.S., Kemp, P.F., and Giovannoni, S.J. (1997) Phylogenetic diversity of marine coastal picoplankton 16S rRNA genes cloned from the continental shelf off Cape Hatteras, North Carolina. Limnol Oceanogr 42: 811-826.

Ronquist, F., and Huelsenbeck, J.P. (2003) MrBayes 3: Bayesian phylogenetic inference under mixed models. Bioinformatics 19: 1572-1574.

Rusch, D.B., Halpern, A.L., Heidelberg, K.B., Sutton, G., Williamson, S.J., Yooseph, S., et al. (2007) The Sorcerer II Global Ocean Sampling expedition: I, The northwest Atlantic through the eastern tropical Pacific. PLoS Biol (submitted).

Schwalbach, M.S., and Fuhrman, J.A. (2005) Wide-ranging abundances of aerobic anoxygenic phototrophic bacteria in the world ocean revealed by epifluorescence microscopy and quantitative PCR. Limnol Oceanogr 50: 620-628.

Schwalbach, M.S., Brown, M., and Fuhrman, J.A. (2005) Impact of light on marine bacterioplankton community structure. Aquat Microb Ecol 39: 235-245.

Sieracki, M.E., Gilg, I.C., Thier, E.C., Poulton, N.J., and Goericke, R. (2006) Distribution of planktonic aerobic anoxygenic photoheterotrophic bacteria in the northwest Atlantic. Limnol Oceanogr 51: 38-46.

Swingley, W.D., Gholba, S., Mastrian, S.D., Matthies, H.J., Hao, J., Ramos, H., et al. (2007) The complete genome sequence of Roseobacter denitrificans reveals a mixotrophic as opposed to photosynthetic metabolism. J Bacteriol (in press).

Teeling, H., Waldmann, J., Lombardot, T., Bauer, M., and Glockner, F.O. (2004) TETRA: a web-service and a stand-alone program for the analysis and comparison of tetranucleotide usage patterns in DNA sequences. BMC Bioinformatics 5: 163.

Venter, J.C., Remington, K., Heidelberg, J., Halpern, A.L., Rusch, D., Eisen, J.A., et al. (2004) Environmental genome shotgun sequencing of the Sargasso Sea. Science 304: 66-74.

Waidner, L.A., and Kirchman, D.L. (2005) Aerobic anoxygenic photosynthesis genes and operons in uncultured bacteria in the Delaware River. Environ Microbiol 7: 18961908.

Wall, M.K., Mitchenall, L.A., and Maxwell, A. (2004) Arabidopsis thaliana DNA gyrase is targeted to chloroplasts and mitochondria. Proc Natl Acad Sci USA 101: 7821-7826.
Walsh, D.A., Bapteste, E., Kamekura, M., and Doolittle, W.F. (2004) Evolution of the RNA polymerase B' subunit gene $\left(r p o B^{\prime}\right)$ in Halobacteriales: a complementary molecular marker to the SSU rRNA gene. Mol Biol Evol 21: 23402351.

Yooseph, S., Sutton, G., Rusch, D.B., Halpern, A.L., Williamson, S.J., Remington, K., et al. (2007) The Sorcerer II Global Ocean Sampling expedition: expanding the universe of protein families. PLOS Biol (in press).

Yurkov, V.V., and Beatty, J.T. (1998) Aerobic anoxygenic phototrophic bacteria. Microbiol Mol Biol Rev 62: 695-724.

Yutin, N., and Béjà, O. (2005) Putative novel photosynthetic reaction center organizations in marine aerobic anoxygenic photosynthetic bacteria: insights from environmental genomics and metagenomics. Environ Microbiol 7: 20272033.

Yutin, N., Suzuki, M.T., and Béjà, O. (2005) Novel primers reveal a wider diversity among marine aerobic anoxygenic phototrophs. Appl Env Microbiol 71: 8958-8962.

\section{Supplementary material}

The following supplementary material is available for this article online:

Fig. S1. Comparisons between pufM, pufL and bchX GOS data.

A. The reads associated with pufM (orange), pufL (blue) and bchX (green) genes.

B. pufM (orange), pufL (blue) and bchX (green) read equivalents. $X$-axes represent sampling site numbers in the same order as at Figs 4 and 6.

Fig. S2. The use of $g y r A$ and $r p o B$ genes as alternative bacteria identifiers. Aerobic anoxygenic photosynthetic bacteria abundances normalized by recA (orange), gyrA (blue) and $r p o B$ (green). $X$-axis represents sampling site numbers in the same order as at Figs 4 and 6.

Table S1. GOS sampling site descriptions.

Table S2. Contributions of each GOS station to pufMcontaining scaffolds revealed in this study.

Doc S1. An example of read equivalent calculation in station 8 (for the pufM gene).

This material is available as part of the online article from http://www.blackwell-synergy.com

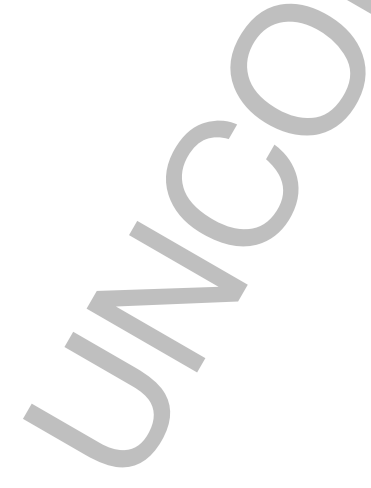




\begin{tabular}{|l|l|}
\hline \multicolumn{2}{|c|}{ SNP Best-set Typesetter Ltd. } \\
\hline Journal Code: EMI & Proofreader: Jason \\
\hline Article No: 1265 & Delivery date: 14 February 2007 \\
\hline Page Extent: 12 & Copyeditor: Edmond \\
\hline
\end{tabular}

\section{AUTHOR QUERY FORM}

Dear Author,

During the preparation of your manuscript for publication, the questions listed below have arisen. Please attend to these matters and return this form with your proof.

Many thanks for your assistance.

\begin{tabular}{|c|c|c|}
\hline $\begin{array}{l}\text { Query } \\
\text { References }\end{array}$ & Query & Remark \\
\hline $\mathrm{q} 1$ & Au: Please provide the author name(s) for the unpublished data. & \\
\hline q2 & $\begin{array}{l}\text { Au: Throughout the article, Figure } 6 \text { has been changed to Figure } 5 \text {, while } \\
\text { Figure } 5 \text { has been changed to Figure } 6 \text {, so that they appear in sequence. }\end{array}$ & \\
\hline q3 & Au: Please clarify what the asterisk means here. & \\
\hline q4 & Au: (Case et al. 2007) Please update the volume number and the page range. & \\
\hline q5 & $\begin{array}{l}\text { Au: (Koblízek et al. 2006) Please update the volume number and the page } \\
\text { range. }\end{array}$ & \\
\hline q6 & Au: (Ludwig et al. 2004) Please confirm the author group is correct. & \\
\hline q7 & $\begin{array}{l}\text { Au: (Rusch et al. 2007) 'submitted' has been changed to } 2007 \text {. The 'submitted' } \\
\text { paper should not be include in the list unless it has been accepted for } \\
\text { publication. Please provide more details if it has been accepted for publication; } \\
\text { otherwise, please remove it from the list and cite it in the text only. }\end{array}$ & \\
\hline q8 & $\begin{array}{l}\text { Au: (Swingley et al. 2007) Please provide the volume number and the page } \\
\text { range if available. }\end{array}$ & \\
\hline q9 & $\begin{array}{l}\text { Au: (Yooseph et al. 2007) Please provide the volume number and the page } \\
\text { range if available. }\end{array}$ & \\
\hline
\end{tabular}




\section{Please correct and return this set}

Please use the proof correction marks shown below for all alterations and corrections. If you wish to return your proof by fax you should ensure that all amendments are written clearly in dark ink and are made well within the page margins.

\begin{tabular}{|c|c|c|}
\hline Instruction to printer & Textual mark & Marginal mark \\
\hline Leave unchanged & ... under matter to remain & ( ) \\
\hline $\begin{array}{l}\text { Insert in text the matter } \\
\text { indicated in the margin }\end{array}$ & $h$ & $\begin{array}{l}\text { New matter followed by } \\
h \text { or } h \otimes\end{array}$ \\
\hline Delete & $\begin{array}{l}\text { I through single character, rule or underline } \\
\text { or }\end{array}$ & $\sigma$ or $\sigma / \otimes$ \\
\hline $\begin{array}{l}\text { Substitute character or } \\
\text { substitute part of one or } \\
\text { more word(s) }\end{array}$ & / through letter or & $\begin{array}{l}\text { new character / or } \\
\text { new characters / }\end{array}$ \\
\hline Change to italics & — under matter to be changed & $\leftarrow$ \\
\hline Change to capitals & $\equiv$ under matter to be changed & $\equiv$ \\
\hline Change to small capitals & $=$ under matter to be changed & $=$ \\
\hline Change to bold type & $\sim$ under matter to be changed & $\sim$ \\
\hline Change to bold italic & $\approx$ under matter to be changed & $\underline{s i n}$ \\
\hline Change to lower case & Encircle matter to be changed & $\not$ \\
\hline Change italic to upright type & (As above) & \\
\hline Change bold to non-bold type & (As above) & \\
\hline Insert 'superior' character & $\begin{array}{l}\text { I through character or } \\
K \text { where required }\end{array}$ & $\begin{array}{l}y^{\prime} \text { or } y \\
\text { under character } \\
\text { e.g. } y^{2} \text { or } y^{2}\end{array}$ \\
\hline Insert 'inferior' character & (As above) & $\begin{array}{l}\text { L } \\
\text { over character } \\
\text { e.g. } \hat{\imath}\end{array}$ \\
\hline Insert full stop & (As above) & $\odot$ \\
\hline Insert comma & (As above) & , \\
\hline Insert single quotation marks & (As above) & $\begin{array}{l}\dot{y} \text { or } \dot{X} \text { and/or } \\
\dot{y} \text { or } \dot{X}\end{array}$ \\
\hline Insert double quotation marks & (As above) & $\begin{array}{l}\dddot{y} \text { or } \ddot{x} \text { and/or } \\
\ddot{y} \text { or } \ddot{x}\end{array}$ \\
\hline Insert hyphen & (As above) & $1-1$ \\
\hline Start new paragraph & $\digamma$ & 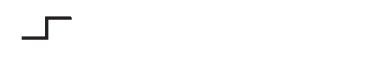 \\
\hline No new paragraph & $\infty$ & $\omega$ \\
\hline Transpose & $\sqcup$ & ᄃ \\
\hline Close up & linking $\bigcirc$ characters & \\
\hline $\begin{array}{l}\text { Insert or substitute space } \\
\text { between characters or words }\end{array}$ & $\begin{array}{l}\text { I through character or } \\
\Lambda \text { where required }\end{array}$ & \\
\hline $\begin{array}{l}\text { Reduce space between } \\
\text { characters or words }\end{array}$ & $\begin{array}{l}\text { between characters or } \\
\text { words affected }\end{array}$ & $\uparrow$ \\
\hline
\end{tabular}

